\section{Yeasts and yeast-like fungal contaminants of water used for domestic purposes in Jos, Nigeria}

\author{
Grace Mebi Ayanbimpe, Victoria Eyiojo \\ Abbah, Clement Akpenpuun lor \\ Medical Microbiology Department, \\ University of Jos, Nigeria
}

\begin{abstract}
Water used for domestic purposes is ideally required to be free from contaminants. Various contaminants have frequently affected the quality of such water. Water samples were obtained from 150 sources including 72 wells, 60 streams, 17 taps, and one borehole, randomly selected from five residential areas in Jos, Nigeria. Structured questionnaires and one-toone interview was used to obtain information on features of location and use of facilities in each area. Eighty (53.3\%) water sources were contaminated, predominantly wells (70.8\%). The locations (identified in code) with the highest number of contaminated sources were AGO (60.0\%), GBU (56.7\%) and FGD (56.7\%). AGD and FGD also had the highest ratio of households to one water source (25:1). Eightytwo fungi were isolated, predominantly Candida tropicalis (23.2\%), Candida lipolytica (10.9\%) and Rhodotorula sp (9.7\%). Candida lipolytica was the highest (42.9\%) contaminant in tap water. Rhodotorula $s p$ was found in all types of water sources sampled. Type of water source had a significant effect $(\mathrm{P}<0.05)$ on the presence of some fungi in the water. The residential area (Location) had a significant effect on contamination of water sources by some yeasts. Water sources for domestic use in Jos are contaminated by yeasts and yeast-like fungi. Frequency of use, exposure of the facility to dirt, and contaminations of surroundings contribute to the occurrence of fungi in water sources and, by implication, the prevalence of fungal infections.
\end{abstract}

\section{Introduction}

Fungi and their spores are found in a variety of habitats within the immediate vicinity of human habitation and the surrounding areas. Numerous factors are responsible for the occurrence of fungal infections and the distribution of etiological agents. There are physical and environmental factors which enhance contact with fungal agents and products of their metabolism which have either positive or negative effects on humans.
Water is a universal liquid which is rightly considered a major component of life. It is used by everyone, and has many and different functions. Water used for domestic purposes is ideally required to be free from contaminants which may be detrimental to the well-being of users. This, however, has not been the case since such water has been found to contain a variety of chemical and biological contaminants. ${ }^{1-5}$

Absence of odor, color and taste are vital aspects of water quality which must always be considered as these serve as indicators of water contamination. Microorganisms are introduced and thrive in a number of microhabitats, some of which have been created by man for particular recreational or occupational purposes. Many species or groups of fungi have been found in water used for different purposes, such as drinking, bathing, washing, cooking, etc., obtained from different sources such as wells, taps, streams, swimming pools, and ponds, bore holes and storage tanks. ${ }^{2,4,5}$

Fungi from the air and soil enter water distribution networks from various sources, such as sediments, plants debris, biofilms and animals. Fungi which accumulate in stored water are capable of multiplying and producing toxins in high concentrations, and this may affect the user in several ways. Fungi are capable of attached and unattached growth in water and hence colonize biofilms on pipe materials after a significant period of exposure. ${ }^{3,6}$ Isolation of fungi from water for recreational purposes, bathing, hot tubs, washing and other purposes have been reported. ${ }^{2,3,7}$ Some of these uses serve as avenues along which these organisms spread among users. Water contamination may also be enhanced through poor sanitation and the unhygienic practices and habits of people living in the vicinity of the water facility, especially surface and ground water sources.

Infectious diseases may be transmitted through contaminated water. It has been suggested that several fungal diseases have been caused by drinking water contaminated by volatile products or toxins of fungi..$^{3,8}$ Others, such as wound contamination, skin infections, allergic diseases and ear infections, have also been suggested, and Penicillia, Aspergilli, Fusaria, Acremonium and other keratinophylic fungi, and yeasts are among common fungi found in water. $2,4,6,7,9,10$

Occurrence of fungi in water is reportedly related to the level of water pollution, although some have been reported to be independent of pollution level. ${ }^{10}$ Fungi spores have been found in clean water in protected sheds. ${ }^{4}$ These can be eliminated by proper treatment before drinking and other sensitive uses, although some have been reported to contribute to the biological load of filters. probably making them
Correspondence: Grace Mebi Ayanbimpe,

Medical Microbiology Department, University of Jos, P.M.B. 2084, Jos, Nigeria.

Tel. +2348035894195

E-mail: ayanbimpegm@gmail.com

Key words: fungi contamination, water, domestic purpose.

Conflict of interests: the authors report no potential confict of interests.

Received for publication: 23 0ctober 2011.

Revision received: 17 April 2011.

Accepted for publication: 11 June 2012.

This work is licensed under a Creative Commons Attribution NonCommercial 3.0 License (CC BYNC 3.0).

(C) Copyright G.M. Ayanbimpeet al., 2012

Licensee PAGEPress, Italy

Microbiology Research 2012; 3:e24

doi:10.4081/mr.2012.e24

ineffective and, therefore, affecting water treatment. ${ }^{3}$

There have been persistent problems of water scarcity in many parts of the study area, especially in residential settlements on the outskirts of towns and some parts of the metropolis. As a result, residents resorted using water from various sources irrespective of the quality. These sources include ponds which had been created around streams and other sites made for mining and irrigation purposes. In some communities, few wells are available and consequently there is a heavy demand from residents. The need to control the risk of infection from water for human use is ever increasing, with a growing population of immunocompromised individuals. Understanding the sources and vehicles, as well as modes of spread of fungal pathogens is an essential aspect of epidemiology which is useful in designing proper infection control. Few studies have traced the presence of fungi in water to the immediate sources of contamination and effect on the water quality. The present study investigated environmental sanitation, and usage of facilities by persons in close vicinity to the water facilities, in an attempt to highlight this.

\section{Materials and Methods}

The water samples were obtained from 150 sources made up of 72 wells, 60 streams, 17 taps, and one borehole. These sources were randomly selected from five residential areas in Jos, Nigeria. A common feature of these areas was the high population of residents and few 
water sources. Questionnaires and one-to-one interview were used to investigate the surroundings, in terms of sanitation, frequency of usage and other factors that may predispose water sources to contamination. The communities consisted of 50-250 residential houses; an average of 170 houses per area. A total of 30 water sources were sampled from each location.

\section{Collection and processing of water samples}

Approximately $20 \mathrm{~mL}$ of water was collected in sterile universal bottles from each source. The $\mathrm{pH}$ value was taken for every sample and recorded accordingly. The samples were physically evaluated for color and odor. For tap, borehole and well water, $10 \mathrm{~mL}$ of each sample was filtered through a $0.45 \mu \mathrm{m}$ filter and placed on Sabouraud's dextrose agar supplemented with chloramphenicol $(0.05 \mu \mathrm{m} / \mathrm{mL})$. Another $10 \mathrm{~mL}$ was centrifuged at $3000 \mathrm{rpm}$ for $5 \mathrm{~min}$ and the deposits streaked over the surface of yeast extract glucose chloramphenicol agar. The stream water samples were first diluted serially (3-fold) in sterile distilled water and $0.1 \mathrm{~mL}$ streaked over plates of SDA containing chloramphenicol $(0.05 \mathrm{mg} / \mathrm{mL})$. Cultures were incubated at room temperature $\left(26-30^{\circ} \mathrm{C}\right)$ and observed daily for growth for seven days.

\section{Identification of isolates}

Gross and microscopic morphological characteristics of the isolates were observed in culture, mounted in lactophenol cotton blue stain, and recorded. Further physiological and biochemical tests carried out to identify the yeast isolates included the production of germ tube in serum, chlamydospore production in corn meal tween 80 agar, assimilation and fermentation of carbohydrates, growth at $37^{\circ} \mathrm{C}$, etc. Standard descriptions in mycological texts and manuals were also compared to assist in identification. ${ }^{11,12}$ Data were analyzed using the statistical package for social sciences, SPSS, version 17.0. Pearson's $\chi^{2}$ test, Fisher's exact test and Spearman's correlation test were used to determine significant associations. $P$ values $\leq 0.05$ were considered significant.

\section{Results}

Of the 150 water sources investigated, 80 $(53.3 \%)$ were contaminated with fungi. Species of yeasts were found in multiples in some of the samples. The only borehole sampled was contaminated with Rhodotorula but because it was a single sample, it was not considered in the test for significance. The highest number of contaminated water sources was recorded for wells with 51 (70.8\%) of the 72 wells harboring fungi. This was closely followed by streams with 22 (36.7\%) contaminated (Table 1). $\mathrm{pH}$ range of water from the different sources also varied, while color $(10.0 \%)$ and odor (25.3\%) were observed in some samples (Table 1). The location with the highest number of contaminated water sources was AG0 with $18(60.0 \%)$ of the samples contaminated, followed by GBU and FGD with $56.7 \%$ each. These locations also had the highest ratio of number of households to one water source (25:1). Table 2 shows details of the distribution of contaminated water sources according to location. Eighty-two isolates, made up of 14 species of yeasts and filamentous fungi were obtained from all types of water sources sampled. Candida tropicalis (23.2\%) and Candida lipolytica (10.9\%) were the predominant isolates, occurring in wells, streams and tap water (Table 3 ). This was followed by Rhodotorula species (9.8\%), this was the only isolate from the borehole sampled. Candida lipolytica was the highest isolate from tap water (42.9\%).

Presence of some fungi was significant in the different sources of water samples $(\mathrm{P}<0.05)$. Fungi with significant presence in the water for domestic use include Candida albicans $(\mathrm{P}=0.000)$, Candida parapsilosis $(\mathrm{P}=0.000)$, Candida lusitaniae $(\mathrm{P}=0.000)$, Hansenula anomalia $(\mathrm{P}=0.000)$, Geotrichum candidum $(\mathrm{P}=0.000)$ and $C$. Kefyr $(\mathrm{P}=0.002)$. The water sources did not have a significant effect $(\mathrm{P}>0.05)$ on the presence of others, such as $C$. tropicalis $(\mathrm{P}=0.932)$.

The location of water source also affected the presence of some fungi in the water. Occurrence of the following fungi was significantly affected by the location of water source: Candida albicans $(\mathrm{P}=0.005)$, Candida kefyr $(\mathrm{P}=0.022)$, Candida parapsilosis $(\mathrm{P}=0.000)$, Candida tropicalis (0.000) and Geotrichum candidum $(\mathrm{P}=0.000)$. Others were not significantly affected by location of water source and include Candida guilliermondii $(\mathrm{P}=0.124)$, Candida lusitaniae $(\mathrm{P}=0.220)$, Candida lipoly-

Table 1. Rate of contamination of water sources in the study area.

$\begin{array}{lccccc}\text { Water source } & \text { pH range } & \text { Number sampled } & \text { Odour present (\%) } & \text { Colour present (\%) } & \text { Number } \\ \text { contaminated (\%) }\end{array}$

Table 2. Distribution of contaminated water sources according to location.

\begin{tabular}{|c|c|c|c|c|}
\hline Location* & $\begin{array}{c}\text { Approximate ratio } \\
\text { of households to water source }\end{array}$ & Number of water sources & Number contaminated & Percent (\%) \\
\hline AGO & $25: 1$ & 30 & 18 & 60.0 \\
\hline GBU & $20: 1$ & 30 & 17 & 56.7 \\
\hline MZA & $25: 1$ & 30 & 16 & 53.3 \\
\hline LRT & $20: 1$ & 30 & 12 & 40.0 \\
\hline FGD & $25: 1$ & 30 & 17 & 56.7 \\
\hline Total & $23: 1^{\circ}$ & 150 & 80 & 53.3 \\
\hline
\end{tabular}

* Not actual names of the locations. ${ }^{\circ}$ Mean ratio of households to water source. 
tica $(\mathrm{P}=0.285)$, Saccharomyces cerevisae $(\mathrm{P}=0.204)$, Hansenula anomalia $(\mathrm{P}=0.640)$, Cryptococcus laurentii $(\mathrm{P}=0.610)$ and Trichosporon sp $(\mathrm{P}=0.081)$.

Poor location and maintenance of water sources, unhygienic practices around water sources, such as defecation by both humans and animals, washing of all types of articles and materials, including clothes, cars and motorcycles, bathing around wells and in streams, irrigation during the dry season, frequent overuse, using dirty vessels to draw water, and lack of proper coverings for the wells were observed factors which may contribute to water contamination. Also, domestic sewage is discharged into some of the streams and refuse dumps are located in close proximity to some water sources.

\section{Discussion}

The occurrence of fungi in water used for domestic purposes in the study area was quite high contrary to results obtained elsewhere. Two major sources, well and stream water, upon which large populations of residents depend, had the highest contamination rates. The avenues for contamination may have been the unsanitary use of containers for drawing water, frequency of use, and exposure of facility to dirt, animals and flooding. Waste matter may have been washed into the wells and streams from the surrounding environment by flooding and windstorms, as the majority of the wells had no proper coverings and are situated in locations close to sources of biological contaminants which may easily discharge into them. It is obvious that proper construction, maintenance and protection of wells and other sources of water for human use can help prevent the spread of waterborne infections. ${ }^{13-15}$ The streams, on the other hand, are visited by a large number of people for activities ranging from bathing to washing, and even irrigational purposes, especially during the dry season when most wells are dry. The local geology and ecosystem, as well as human factors, such as overuse (which may lower the level of the water), sewage dispersion, industrial pollution, and use of water bodies as a heat sink, have been recognized to influence water quality. ${ }^{3,7}$ Our findings support the findings of other researchers in advocating the continued protection of domestic water supplies through the use of sanitary and watershed surveys to determine if there is any past or current activity that places the water supply at risk of contamination. ${ }^{16}$ It is an established fact that all categories of sewage are likely to carry pathogenic microorganisms and, as observed in this study and other reports, ${ }^{7}$ in many parts of the

Table 3. Distribution of yeasts and yeast-like fungi isolated from various water sources examined.

\begin{tabular}{lccccc}
\hline Fungus & Tap & Stream & Well & Borehole & Total \\
Candida albicans & 0 & 2 & 4 & 0 & 6 \\
Candida kefyr & 1 & 3 & 2 & 0 & 6 \\
\hline Candida parapsilosis & 0 & 5 & 0 & 0 & 5 \\
Candida tropicalis & 0 & 3 & 16 & 0 & 19 \\
\hline Candida lusitaenia & 0 & 0 & 1 & 0 & 1 \\
Candida guilliermondii & 0 & 0 & 1 & 0 & 1 \\
\hline Candida stelatoidea & 1 & 0 & 3 & 0 & 4 \\
Candida lipolytica & 3 & 1 & 5 & 0 & 9 \\
Trichosporon sp & 0 & 0 & 7 & 0 & 7 \\
Cryptococcus laurentii & 0 & 0 & 2 & 0 & 2 \\
Saccharomyces cerevisae & 0 & 1 & 1 & 0 & 2 \\
Rhodotorula sp & 2 & 1 & 4 & 1 & 8 \\
\hline Geotrichum candidum & 0 & 1 & 4 & 0 & 5 \\
Candida krusei & 0 & 6 & 1 & 0 & 7 \\
Total & 7 & 23 & 51 & 1 & 82 \\
\hline
\end{tabular}

world, sewage and wastewater are also disposed of in rivers, streams and the sea. In developed countries, sewage collection and treatment is typically subject to local, state and federal regulations and standards. ${ }^{17}$ There are no such established regulations and standards in the study area, and where they do exist, very few people are aware of them. The method of disposal of both liquid and solid waste in the study area requires proper monitoring by experts to ensure the safety of residents.

$\mathrm{pH}$ values of well and stream water were mostly alkaline, indicating that they may have been contaminated by sewage, soil and fecal matter in their surroundings. This may have led to serious pollution of the receiving water. This confirms the observation made by some researchers $^{7}$ that the disposal of animal wastes on land is a potential nonpoint source of water degradation. Water degradation and human health is a major concern when considering the disposal of large quantities of both animal and human waste.

The high occurrence of such organisms as Geotrichum sp and some species of Candida from areas close to some wells demands attention because the majority of residents not only bath with well water, but also drink without boiling it or treating it in any other way. Water has been identified as an avenue for spread of a number of fungal infections, particularly among hospital patients. ${ }^{9,14}$ There was a significant difference between the type of water source and the rate of occurrence of some fungi, in contrast to findings elsewhere ${ }^{4}$ probably because of the slight difference in the types of water sources examined in the two studies.
Tap water was the least contaminated by yeasts; contamination included Candida lipolytica, Rhodotorula and Saccharomyces cerevisae. Tap water, treated by chlorination before being piped to the domestic water supply, may not have favored many fungi because, as reported elsewhere, treatment significantly reduced the numbers of fungi, including yeasts, in the distribution system. Candida lipolytica probably occurred in large numbers in tap water because of its ability to attach to soft deposits in pipelines. Soft deposits have been reported as key sites for fungi which have also been reported to be capable of attached and unattached colonization in water. ${ }^{6,15} C$. lipolytica was reportedly capable of producing large amounts of viscid slime material in glucose-containing solution, likely responsible for the ability of the yeast to adhere to surfaces. ${ }^{16}$ C. Lipolytica, Rhodotorula sp and Trichosporon are among emerging opportunistic pathogens, particularly in immunocompromised patients. ${ }^{18-20}$ Some cases of fungemia associated with catheters, endocarditis, peritonitis, meningitis, and endophthalmitis are infections caused by these fungi and resistances to antifungal agents have been reported. ${ }^{9,19,20}$

\section{Conclusions}

The water sources examined in Jos are contaminated by yeasts and yeast-like fungi, and hence not completely safe for domestic use. Frequency of use, exposure of the facility to 
dirt, and contaminations of surrounding areas contribute to the occurrence of fungi in water sources and, by implication, the prevalence of fungal infections. Based on the above findings and observations, we suggest further studies to determine the prevalence of infections resulting from the use of water sources from the study area should be carried out. Also, similar studies should be carried out to detect other microorganisms other than yeasts in domestic water sources. Rapid, modern techniques are recommended to facilitate the detection of more microorganisms which may be present in water for domestic use.

\section{References}

1. Vladmir K, Tomas 0, Roman G. Background level of pops in ground water assessed on chemical and toxicity analysis of exposed semi permeable membrane devices. Air Soil Water Res 2009;2:1-14.

2. Minnesota Department of Health. The Minnesota Department of Health Well Management Bacterial Safety of Well Water. 2011. Available from: http://www.health.state.mn.us/divs/eh/well s/waterquality/bacteria.html. Accessed on: December 15, 2010.

3. Russell R, Paterson M, Lima N. Fungal contamination of drinking water. Water Encyclopedia. Hoboken: John Wiley \& Sons, Inc.; 2005.
4. de Castro J, Figuera F. Fungal contamination of water and water-related surfaces in three hospital wards with immunocompromised patients at risk for invasive fungal infections. J Infect Prev 2010;11:36-41.

5. Adewoye S0. Effects of detergent effluent discharges on the aspect of water quality of ASA River, Ilorin, Nigeria. Agric Biol J N Am 2010;1:731-6.

6. Gottlich E, van der Lubbe W, Lange B, et al. Fungal flora in groundwater-derived public drinking water. Int $\mathbf{J}$ Hyg Environ Health 2002;205:269-79.

7. Hinzelin F, Block JC. Yeasts and filamentous fungi in drinking water Environmental Technology 1985:6:101-6.

8. Anaissie F, Costa R.. Nosocomial aspergillosis is waterborne. Clin Infect Dis 2001;33:1546-9.

9. Domenico D, Ferdinando R, Eugenio P, et al. Catheter-related candidemia caused by Candida lipolytica in a patient receiving allogeneic bone marrow transplantation. J Clin Microbiol 2002;40:1381-6.

10. Ulfig K, Vidal P. A preliminary study on the distribution of keratinophilic fungi in bottom deposits of the Catalonian waters. Stvdia Botanica 1994;13:107-8.

11. Larone DH. Medically important fungi: a guide to identification 3ed. Washington DC: ASM Press; 1995.

12. DeHoog GS, Guarro J, Gene J, Figueras MJ. Atlas of clinical fungi. Atlas Version 2004. Computer Science, University of Wurzburg Germany.
13. Baddley JW, Pappas PG, Smith AC, Moser SA. Epidemiology of Aspergillus terreus at a University Hospital. J Clin Microbiol 2003;41:5525-9.

14. Okpako EC, Osuagwu AN, Duke AE, Ntui VO. Prevalence and significance of fungi in sachet and borehole drinking water in Calabar, Nigeria. Afr J Microbiol Res 2009;3:56-61.

15. Kelley J, Kinsey G, Paterson R, et al. Identification and control of fungi in distribution systems. Denver: AWWA Research Foundation and American Water Works Association; 2003.

16. Zacheus OM, Lehtola MJ, Korhonen LK, Martikainen PJ. Soft deposits, the key site for microbial growth in drinking water distribution networks. Water Res 2001;35: 1756-7.

17. Waterborne Disease Center Department of Biostructure and Function, University of Connecticut Health Center. Regulation in Drinking Water Supply Fact Sheet Series. 2002

18. Pereira VJ, Basillio MC, Fernandes D, et al. Occurrence of filamentous fungi and yeasts in three different drinking water sources. Water Res 2009;43:3813-9.

19. Greenberger PA. Mold-induced hypersensitivity pneumonitis. All Asthma Proc 2004; 25:219-23.

20. Diekema DJ, Petroelje B, Messer SA, et al. Activities of available and investigational antifungal agents against rhodotorula species. Clin Microbiol 2005;43:476-8. 